\title{
Cyclic Nucleotides in the Rat Brain during Lidocaine Infusion
}

\author{
Kyoko Yamada \\ Department of Anesthesiology, Yamaguchi University School of Medicine, Ube, Yamaguchi 755, Japan \\ (Received November 9; revised December 8, 1981)
}

\begin{abstract}
The concentrations of cyclic $3^{\prime}, 5^{\prime}$-guanosine monophosphate (cGMP) and cyclic $3^{\prime}, 5^{\prime}$-adenosine monophosphate (cAMP) in the cerebellar and cerebral cortex were measured during lidocaine infusion in rats. The rats were divided into three groups, control, lidocaine $(0.74 \mathrm{mg} / \mathrm{min})$ and bicuculline $(1.2 \mathrm{mg} / \mathrm{kg})$. The lidocaine group was divided into four stages according to the EEG pattern; desynchronized, synchronized, seizure and recovery. At the desynchronized and synchronized stages, cGMP and cAMP concentrations in both cerebellar and cerebral cortex remained unchanged except for a modest decrease in cerebral cortex at the desynchronized stage. At the seizure stage, cerebellar cGMP increased from $5.2 \pm 0.9$ to $9.2 \pm 1.4 \mathrm{pmols} / \mathrm{mg}$ protein and cerebellar cAMP decreased from $8.9 \pm 0.6$ to $6.9 \pm 0.6 \mathrm{pmols} / \mathrm{mg}$ protein. These changes in concentrations at the seizure stage returned to the control levels at the recovery stage. With bicuculline, cGMP and cAMP concentrations strikingly increased in both cerebellar and cerebral cortex. These results suggested that the cerebellum contributed to lidocaine-induced seizures.
\end{abstract}

Key Words: Anesthetics; lidocaine, Brain; cyclic nucleotides, convulsions, bicuculline

Introduction

Recent investigations have revealed that a variety of synaptic functions are mediated through $3^{\prime}, 5^{\prime}$-guanosine monophosphate (cGMP) and $3^{\prime}, 5^{\prime}$ - adenosine monophosphate (cAMP) mechanisms ${ }^{1)}$. Alteration of these mechanisms may account for the excitation and depression of electrical activity of the brain known to occour during general anesthesia. Thus, previous studies found the changes in cyclic nucleotides concentrations in the brain during general anesthesia ${ }^{2-8)}$.
Intravenous lidocaine may cause sequential changes in behavior and EEG following a progressive increase in blood concentrations in both men and animals ${ }^{9}$. Maekawa et al ${ }^{10)}$ reported in rats that, with increasing dose of this drug, EEG becomes desynchronized, synchronized and then shows a seizure pattern, suggesting complex alteration of neuronal function. However, we are unaware of any report which examined the effects of lidocaine on cyclic nucleotides concentrations in the brain. Accordingly, the present study was designed to evaluate cAMP and 
cGMP concentrations in the cerebellar and cerebral cortex during lidocaine infusion at different EEG patterns, and to compare the effects of lidocaine-induced seizures with those induced by bicuculline. We found that lidocaine-induced seizures were accompanied by significant changes in cerebellar cyclic nucleotide concentrations.

\section{Methods}

Thirty five unstarved male Wister rats, weighing 290 to $400 \mathrm{~g}$, were used. Experimental methods of animal preparation were the same as those described previously ${ }^{10)}$. Briefly, the rats were anesthetized with halothane and nitrous oxide in oxygen, and ventilated with an animal respirator. The femoral artery and vein were catheterized for monitoring direct arterial blood pressure, blood sampling, and the injection of drug. The skull was exposed and the EEG was recorded from bipolar frontoparietal leads, using screw electrodes. After completion of the operation, halothane was discontinued and the rats were ventilated with $70 \%$ nitrous oxide in oxygen. Thereafter at least $30 \mathrm{~min}$ were allowed to elapse in order to obtain stable blood pressure, blood gas values, and body temperature. Blood samples for gas analysis (BMS2 $\mathrm{MK}^{\mathrm{B}}$ blood micro system and PHM $72 \mathrm{MK}^{\circledR}$ digital acid-base analyzer, Radiometer Lted., Denmark) were taken at frequent intervals, including a sample immediately before freezing of the brain. The concentration of lidocaine in blood taken immediately before freezing of the brain, was analyzed by gas chromatography. Blood loss due to sampling was replaced by fresh heparinized blood. Body temperature was maintained at $37.1 \pm 0.1^{\circ} \mathrm{C}$ (mean \pm SEM) by a warming blanket.

The rats were randomized into three groups; control, lidocaine (infusion at a constant rate of $0.74 \mathrm{mg} / \mathrm{min}$ ) and bicuculline (single intravenous injection of $1.2 \mathrm{mg} / \mathrm{kg}$ ). The lidocaine group was randomly divied into four stages according to the EEG pattern; desynchronized, synchronized, seizure and recovery as in the previous study ${ }^{10}$. The brain was frozen 1,5 and $1 \mathrm{~min}$ after the onset of desynchronized, synchronized and seizure patterns, respectively. In the recovery group the brain was frozen $60 \mathrm{~min}$ after the end of seizure. With bicuculline, the brain was frozen $1 \mathrm{~min}$ after the onset of seizure. In all rats, the brain was frozen in situ by pouring liquid nitrogen over the intact skull bone. Cerebellar and cerebral cortical tissue samples were stored and dissected in liquid nitrogen. After weighing, the tissues (20-40 mg) were homogenized in $4-6 \mathrm{ml}$ of cold $10 \%$ trichloroacetic acid (TCA) in the cryo-stat $\left(-20^{\circ} \mathrm{C}\right)$ and centrifuged at $3000 \mathrm{rpm}$ for $10 \mathrm{~min}$ at $0^{\circ} \mathrm{C}$. TCA in each sample was extracted 6 times with $5 \mathrm{ml}$ of watersaturated diethyl ether. Then the residual ether was removed by placing the samples in water bath at $80^{\circ} \mathrm{C}$. The cyclic nucleotides in the extract $(100$ $\mu 1)$ were succinylated by the sequential addition of succinic anhydride and triethylamine. One hundreds $\mu \mathrm{l}$ of each succinylated samples was mixed 900 $\mu l$ of $0.05 \mathrm{M}$ acetate buffer ( $\mathrm{pH}$ 6.2), and a portion $(200 \mu \mathrm{l})$ of the mixture was assayed for cyclic nucleotides by radioimmunoassay, using Hoechist Japan's commercial kits based on the method of Steiner et $\mathrm{al}^{11}$. The TCA insoluble pellet from each tissue sample was assayed for protein, using the method of Lowry et $\mathrm{al}^{12)}$. Statistical differences were compared between the control and the drug groups using unpaired Student t-test. $\mathrm{P}<0.05$ was considered to be significant.

\section{Results}

EEG patterns (Figure 1) and physiological parameters (Table 1) are essentially the same as those reported in our previous report ${ }^{10)}$. Table 2 summarizes the concentrations of cGMP and cAMP in the cerebellar and cerebral cortex. In the lidocaine group at non-seizure dose, cGMP and cAMP in both cerebellar and cerebral cortex remained unchanged except for a decrease in cerebral cGMP at the desynchronized stage. At seizure dose, cerebellar cAMP decreased and cerebellar cGMP increased significantly. In the bicuculline group, cAMP and cGMP strikingly increased in both cerebellar and cerebral cortex.

\section{Discussion}

The observed changes in cyclic nucleotide concentrations clearly indicated the contribution of the cerebellum to lidocaine-induced seizures. Regulation of neuronal activity through cyclic nucleotides has been extensi- 


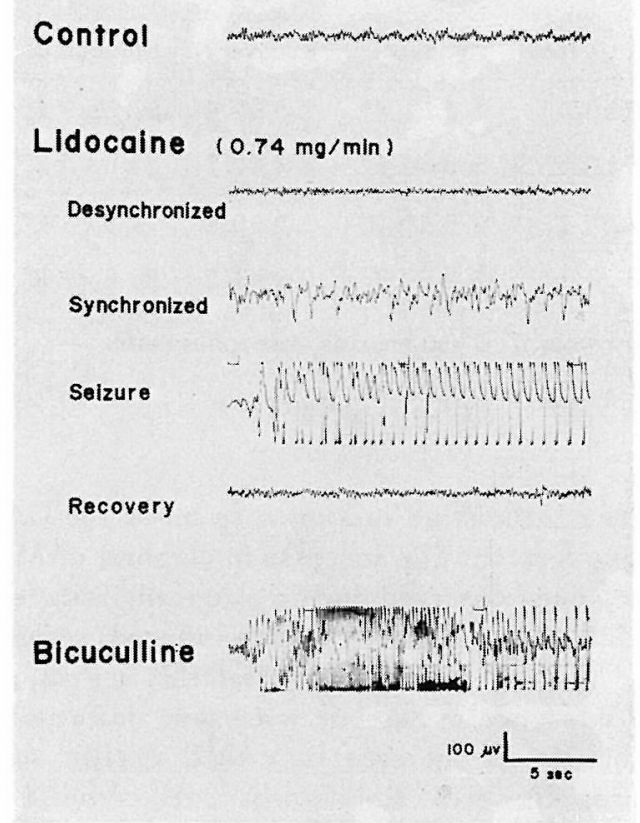

Fig. 1 Representative EEG changes with increasing dose of lidocaine and EEG seizures with lidocaine and bicuculline. EEGs were recorded immediately before freezing of the brain.

vely studied in the cerebellum ${ }^{13)}$. Purkinje cells are the pivotal neurons of the cerebellar cortex which influence muscular activity through their inhibitory effect on the subcortical nuclei and receive at least three different inputs ${ }^{14)}$. First, Purkinje cells re- ceive excitatory input through climbing and mossy fibers, and it has been postulated that the second messenger of excitatory transmitters is cGMP ${ }^{15}$. Second, Purkinje cells are regulated by a neuronal network within the cortex which inhibits their activity through the release of $\gamma$-aminobutyric acid (GABA). Thus, cerebellar cGMP is increased when excitatory input is enhanced or when stimulation of GABA receptors is decreased $^{16,17)}$. Third, considerable evidence suggests that the noradrenergic pathway from the locus coeruleus has an inhibitory effect on Purkinje cells which is mediated by $\mathrm{cAMP}^{1)}$. This noradrenaline-mediated inhibitory connection operates through $\beta$-receptors on cerebellar Purkinje cells. Therefore, cerebellar cGMP is altered by drugs that change either the excitatory input or the inhibitory input mediated by the activation of GABA receptors, while cerebellar cAMP is altered by drugs that change inhibitory input mediated by the activation of $\beta$-receptors. The observed increase in cerebellar cGMP and decrease in cerebellar cAMP during lidocaine-induced seizures indicate increased activity of Purkinje cells. It was not the purpose of the present study to clarify the mechanism of action of lidocaine on cerebellar cGMP levels. However, we can propose possible sites where lidocaine may act to increase cGMP. Ikeda et $\mathrm{al}^{18)}$ reported that a seizure dose of lidocaine may

Table 1 Physiological Parameters and Lidocaine Concentrations of Arterial Blood

\begin{tabular}{c|c|c|c|c|c|c}
\hline \hline & $\begin{array}{c}\text { Control } \\
(\mathrm{n}=5)\end{array}$ & $\begin{array}{c}\text { Desynchronized } \\
(\mathrm{n}=6)\end{array}$ & $\begin{array}{c}\text { Synchronized } \\
(\mathrm{n}=6)\end{array}$ & $\begin{array}{c}\text { Seizure } \\
(\mathrm{n}=6)\end{array}$ & $\begin{array}{c}\text { Recovery } \\
(\mathrm{n}=6)\end{array}$ & $\begin{array}{c}\text { Bicuculline } \\
(\mathrm{n}=6)\end{array}$ \\
\hline $\mathrm{PaO}_{2}$ (torr) & $123 \pm 2$ & $117 \pm 3$ & $106 \pm 2$ & $109 \pm 2$ & $114 \pm 5$ & $124 \pm 7$ \\
$\mathrm{PaCO}_{2}$ (torr) & $38.3 \pm 1.4$ & $40.6 \pm 1.6$ & $38.5 \pm 1.2$ & $38.1 \pm 1.5$ & $40.5 \pm 1.1$ & $23.3 \pm 1.3^{*}$ \\
$\mathrm{pHa}$ & $7.43 \pm 0.02$ & $7.43 \pm 0.02$ & $7.41 \pm 0.03$ & $7.40 \pm 0.02$ & $7.43 \pm 0.01$ & $7.56 \pm 0.02^{*}$ \\
$\mathrm{Ht}(\%)$ & $42 \pm 1$ & $42 \pm 1$ & $41 \pm 1$ & $41 \pm 2$ & $43 \pm 1$ & $47 \pm 2^{*}$ \\
$\mathrm{MAP}$ (torr) & $112 \pm 11$ & $121 \pm 6$ & $103 \pm 3$ & $100 \pm 7$ & $125 \pm 5$ & $169 \pm 6^{*}$ \\
$\begin{array}{c}\text { Lidocaine } \\
(\mu \mathrm{g} / \mathrm{ml})\end{array}$ & 0 & $2.9 \pm 0.4$ & $4.3 \pm 0.6$ & $9.4 \pm 0.9$ & $1.2 \pm 0.1$ & 0 \\
\hline
\end{tabular}

MAP: mean arterial pressure. The values are means $\pm \mathrm{SEM}$.

* Significantly different from control $(\mathrm{P}<0.05)$. 
Table 2 Cyclic Nucleotides Concentrations of Brain Tissue ( $\mathrm{pmol} / \mathrm{mg}$ protein)

\begin{tabular}{rc|c|c|c|c|c|c}
\hline & & Control & Desynchronized & Synchronized & Seizure & Recovery & Bicuculline \\
\hline \multirow{2}{*}{ Cerebellum } & cGMP & $5.2 \pm 0.9$ & $3.0 \pm 0.1$ & $3.0 \pm 0.4$ & $9.2 \pm 1.4^{*}$ & $2.9 \pm 0.4$ & $97.5 \pm 9.1^{*}$ \\
& cAMP & $8.9 \pm 0.6$ & $8.4 \pm 0.2$ & $7.5 \pm 0.6$ & $6.9 \pm 0.6^{*}$ & $8.4 \pm 0.7$ & $25.6 \pm 2.2^{*}$ \\
\hline \multirow{2}{*}{ Cerebrum } & cGMP & $1.5 \pm 0.1$ & $1.2 \pm 0.1^{*}$ & $1.3 \pm 0.1$ & $1.5 \pm 0.1$ & $1.5 \pm 0.1$ & $3.9 \pm 0.2^{*}$ \\
& cAMP & $17.3 \pm 0.8$ & $16.1 \pm 1.2$ & $14.6 \pm 1.1$ & $15.2 \pm 0.7$ & $16.9 \pm 1.3$ & $25.6 \pm 2.2^{*}$ \\
\hline
\end{tabular}

cAMP: cyclic $3^{\prime}, 5^{\prime}$-adenosine monophosphate; cGMP: cyclic $3^{\prime}, 5^{\prime}$-guanosine monophosphate.

The values are mean $\pm S E M$.

* Significantly different from control $(\mathrm{P}<0.05)$.

inhibit the release of GABA from the presynaptic terminal, thereby decreasing the stimulation of the GABA receptor. If this occurs in the cerebellar cortex, there should be an increase in cerebellar cGMP. However, a drug could alter cerebellar cGMP indirectly, by a primary action on brain areas outside the cerebellum that have projection to the inferior olivary nuclei or the pontine nuclei whose neurons communicate directly with the cerebellar cortex through climbing or mossy fibers, respectively. Decrease in cerebellar cAMP during lidocaine-induced seizures may indicate de-inhibition of the noradrenergic pathway, and hence an increase in the activity of Purkinje cells. Thus, our results do not necessarily mean that the cerebellum is primarily responsible for the initiation of lidocaine-induced seizures, and the increased activity of Purkinje cells observed might be a second manifestation of influences from other parts of brain structures, paticularly the limbic system which is known as a focus of lidocaine-induced seizures $^{9}$. The unchanged cerebellar and cerebral cGMP and cAMP at non-seizure dose of lidocaine except for a small decrease in cGMP at the desynchronized stage, suggests no significant role of neurotransmitter mechanism mediated by cyclic nucleotides in this circumstance. The increase in cGMP during bicuculline-induced seizures in both cerebellar and cerebral cortex was expected since bicuculline is known to block the GA$\mathrm{BA}$ receptor. The increase in cerebral cAMP had been observed during electically induced seizure ${ }^{19)}$ and homocysteine-induced seizur$\mathrm{es}^{20)}$. These authors suggested that activation of adenylate cyclase by adenosine is responsible for an increase in cAMP during seizures. However, Rehnorona et $\mathrm{al}^{21)}$ did not observe an increase in adenosine during bicuculline-induced seizures and concluded that other mechanisms rather than adenosine accumulation seem to be responsible for the increase in cerebral cAMP during neuronal hyperactivity. Observed disparity in cyclic nucleotide concentrations between lidocaine and bicuculline-induced seizures would not be readily explained by the severty of seizures, but rather suggests a qualitative difference between lidocaine and bicucullineinduced seizures.

A non-seizure dose of lidocaine had a depressant effect on the brain, at least from a metabolic viewpoint, which can be related to its general anesthetic effects ${ }^{22)}$. Previous studies revealed a marked change in cyclic nucleotide concentration during halothane, morphine or ketamine anesthesia ${ }^{2)}$. The cerebellar cGMP decreases with halothane and pentobarbital ${ }^{3-7)}$. Therefore, we had anticipated that a non-seizure dose of lidocaine may change cyclic nucleotide concentrations. However, in the present study, decreases in cerebellar cGMP did not reach 
statistical significance, making it difficult to determine the common pathway in the neurotransmitter mechanism with other general anerthetics. Finally, it must be added that in the present study regional differences in cyclic nucleotide concentrations could not be detected, and that there might be significant changes in cyclic nucleotide concentrations in another part of the brain even at a non-seizure dose of lidocaine. In summary, lidocaine-induced seizures were accompanied by an increase in cerebellar cGMP and a decrease in cerebellar cAMP.

The author thanks Prof. Nakazawa, Department of Biochemistry, Yamaguchi University for his helpful criticism and suggestion in the preparation of the manuscript.

\section{References}

1) Nathanson, J.A.: Cyclic nucleotides and nervous system function. Physiol. Rev., $57: 157-$ 256, 1977.

2 ) Dedrick, D.F., Scherer, Y.D. and Biebuyck, J. F.: Use of a rapid brainsampling technique in physiological preparation: Effects of morphine, ketamine and halothane on tissure energy intermediates. Anesthesiology, $42: 651-657,1975$.

3) Nahrwold, M.L., Lust, W.D. and Passonneau, J.V.: Halothane-induced alterations of cyclic nucleotide concentrations in three regions of the mouse nervous system. Anesthesiology, 47 : 423-427, 1977.

4) Nahrwold, M.L., Lust, W.D. and Passonneau, J.V.: Halothane-induced changes in cyclic nucleotide levels in mouse brain. Trans Am. Soc. Neurochem., 9: 98, 1979.

5 ) Paul, M.I., Pauk, G.L. and Ditzion, B.R.: The effect of centrally acting drugs on the concentration of brain adenosine $3^{\prime}, 5^{\prime}$-monophosphate. Pharmacology, 3 : 148-154, 1970.

6 ) Katz, J. and Catravas, G.N.: Cerebellar cGMP levels reduced by morphine and pentobarbital on a dose-and time-dependent basis. Biochem. Pharmacol., 25 : 2543-2546, 1976.

7) Opmmer, F.A., Gumulka, S.W., Dinnendahl, V. and Schonhofer, P.S.: Effects of stimulatory and depressant drugs on cyclic guanosine $3^{\prime}, 5^{\prime}$-monophosphate and adenosine $3^{\prime}, 5^{\prime}$ -monophosphate levels in mouse brain. NaunynSchmiedebergs Arch. Pharmacol., 292 : 259-265, 1976.

8) Triner, L., Vulliemoz, Y., Verosky, M. and Alpert, M.: Halothane effect on cGMP and control of motor activity in mouse cerebellum. Anesthesiology, 54 : 193-198, 1981.

9 ) de Jong, R.H.: Local Anesthetics. Springfield, Charles C Thomas, 1977, pp 84-114.

10) Maekawa, T., Oshibuchi, T., Takeshita, H. and Imamura, A.: Cerebral energy state and glycolytic metabolism during lidocaine infusion in the rat. Anesthesiology, $54: 278-283,1981$.

11) Steiner, A.L., Parker, C.W. and Kipnis, D.M.: Radioimmunoassay for cyclic nucleotides. I. Preparation of antibodies and iodinated cyclic nucleotides. J. Biol. Chem., $247:$ 1106-1113, 1972.

12) Lowry, O.H., Rosebrough, N.J., Farr, A.L. and Randall, R.H.: Protein measurement with the folin phenol reagent. J. Biol. Chem., 193 : 265275, 1951.

13) Eccles, J.C.: The Understanding of the Brain. New York, McGraw-Hill, 1973, pp 104-144.

14) Biggio, G., Brodie, B.B., Costa, E. and Guidotti, A.: Mechanisms by which diazepam, muscimol, and other drugs change the content of cGMP in cerebellar cortex. Proc. Natl. Acad. Sci. USA, $74:$ 3592-3596, 1977.

15) Biggio, G. and Guidotti, A.: Climbing fiber activation and $3^{\prime}, 5^{\prime}$ - cyclic guanosine monophosphate content in cortex and deep nuclei of cerebellum. Brain Res., $107: 365-373,1976$.

16) Costa, E., Guidotti, A., Mao, C.C. and Suria, A.: New concepts on the mechanism of action of benzodiazepines. Life Sci., $17: 167-186$, 1975.

17) Biggio, G., Costa, E. and Guidotti, A.: Pharmacologically induced changes in the $3^{\prime}, 5^{-}$ -cyclic guanosine monophosphate content of rat cerebellar cortex: Difference between apomorphine, haloperidol and harmaline. J. Pharmacol. Exp. Therp., 200:207-215, 1977.

18) Ikeda, M., Harada, S. and Tsujimoto, A.: Prevention of local anesthetic-induced convulsions by $\gamma$-aminobutyric acid. Jpn. J. Pharmacol., 26 (Suppl.): 44, 1976.

19) Llinas, R.: in the Nervous System. ed. Tower, D.B., Raven Press, New York, pp 235-244. 
20) Rehncrona, S., Siesjö, B.K. and Westerberg, E.: Adenosine and cyclic AMP in cerebral cortex of rats in hypoxia, status epilepticus and hypercapnia. Acta Physiol. Scand., 104 : 453-463, 1978.

21) Sattin, A.: Increase in the content of adenosine $3^{\prime}, 5^{\prime}$-monophosphate in mouse forebrain during seizures and prevention of the increase by methylxanthines. $J$. Neurochem., 18:10871096, 1971.
22) Folbergrova, J.: Cyclic $3^{\prime}, 5^{\prime}$-adenosine monophosphate in mouse cerebral cortex during homocysteine convulsions and their prevention by sodium phenobarbital. Brain Res., 92 : 165169, 1975.

23) Sakabe, T., Maekawa, T., Ishikawa, T. and Takeshita, H.: The effects of lidocaine on canine cerebral metabolism and circulation ralated to the electroencephalogram. Anesthesiology, $40: 433-441,1974$. 